\title{
Performance of five molecular methods for monitoring Arcobacter spp
}

\author{
Arturo Levican and María José Figueras*
}

\begin{abstract}
Background: Bacteria belonging to the Arcobacter genus are emerging enteropathogens and potential zoonotic agents. Their taxonomy has evolved very rapidly, and there are presently 18 recorded species. The prevalence of species belonging to Arcobacter is underestimated because of the limitations of currently available methods for species identification.

The aim of this study was to compare the performance of five PCR based methods that target regions of $16 \mathrm{~S}$ rRNA, $23 \mathrm{~S}$ rRNA or gyrA genes to identify Arcobacter species, and to review previous results reported in the literature using these methods.

Results: The five tested methods were found not to be reliable. They misidentified between $16.8 \%$ and $67.4 \%$ of the studied strains; this was dependent upon the target regions of the tested genes. The worst results obtained were for the identification of Arcobacter cryaerophilus and Arcobacter butzleri when the 23S rRNA gene was used as the target. These species were confused with many non-targeted species.
\end{abstract}

Conclusion: Our results suggest that the known diversity of Arcobacter spp. in different environments could be expanded if reliable identification methods are applied in future studies.

Keywords: Arcobacter, Identification, Comparison, Molecular methods, 16 S rRNA-RFLP, m-PCR, 23S rRNA, gyrA

\section{Background}

Arcobacter spp. are emerging enteropathogens and potential zoonotic agents that can be transmitted by food and water [1]. Previous studies have demonstrated a relationship between the presence of arcobacters in water samples and bacterial indicators of faecal pollution $[2,3]$. This genus belongs to the Campylobacteraceae family and was originally proposed by Vandamme et al. in 1991 [4] to accommodate two aerotolerant species (Arcobacter cryaerophilus and Arcobacter nitrofigilis), which had previously been included in the Campylobacter genus. Since 2009, the number of newly described species has risen exponentially, and the genus currently comprises 18 species, eight of which were described in our laboratory [1,5-8].

The identification of Arcobacter spp. by phenotypic testing is difficult. This is because they can easily be confused with Campylobacter spp. [1,9]. This has led to the

\footnotetext{
*Correspondence: mariajose.figueras@urv.cat

Unitat de Microbiologia, Departament de Ciències Mediques Bàsiques, Facultat de Medicina i Ciències de la Salut. IISPV, Universitat Rovira i Virgili, Reus, Spain
}

design of many different molecular detection and identification methods. These are based on conventional PCR, multiplex PCR (m-PCR), Real Time PCR (RT-PCR), Restriction Fragment Length Polymorphism (RFLP), Denaturing Gradient Gel Electrophoresis PCR (DGGEPCR), Fluorescence in situ Hybridisation (FISH) and Matrix Assisted Laser Desorption Ionization Mass Spectrometry (MALDITOF MS); these methods are reviewed by Collado \& Figueras [1]. The majority of PCR based methods [10-13] target the genus, or only Arcobacter butzleri and/or A. cryaerophilus $[1$ and references therein]. Others also include Arcobacter skirrowii $[14,15]$ or Arcobacter cibarius [16]. In 2010, Douidah et al. proposed a new m-PCR method that could identify the five species associated with humans or other mammals, i.e. A. butzleri, A. cryaerophilus, A. skirrowii, A. cibarius and Arcobacter thereius [9]. This m-PCR method was not able to detect Arcobacter trophiarum, which was originally isolated from pigs by De Smet et al. [17]. Therefore, the authors proposed a PCR method targeting the hsp 60 gene for this species. In 2008, Figueras et al. [18] designed an RFLP identification method based on the

\section{Biomed Central}


digestion of the 16S rRNA gene with the MseI endonuclease; this was able to identify the six species so far described (A. butzleri, A. cryaerophilus, A. cibarius, A. skirrowii, A. nitrofigilis, and Arcobacter halophilus). This method was recently updated with the inclusion of additional endonucleases ( $M n l \mathrm{I}$ and $B f a \mathrm{I})$, and is able to identify the 17 Arcobacter spp. described at the time of publication [19]. The prevalence of Arcobacter spp. in different matrices such as water, food, and faeces is underestimated because of the limitations of the identification methods used to recognize all species [1]. Despite this, no study has comparatively evaluated the performance of the most commonly used identification methods. The aim of this study was to test the performance of five molecular identification methods across all Arcobacter spp. The compared methods were selected because they target a higher number of Arcobacter species [9,14-18]. Furthermore, a literature review was performed to analyse the results that have been obtained using these methods since their publication.

\section{Methods}

The five identification methods were compared using 95 different strains, these included type and reference strains, as well as field strains. These strains represented all currently accepted Arcobacter species (Additional file 1: Table S1), but did not include the recently described Arcobacter anaerophilus [8]. The five molecular methods investigated were selected because they targeted a higher number of species. They were as follows: two m-PCRs designed for A. butzleri, A. cryaerophilus, and A. skirrowii [14,15]; a PCR method that targets A. butzleri, A. cryaerophilus, A. skirrowii, and A. cibarius [16]; and two methods that target A. butzleri, $A$. cryaerophilus, A. skirrowii, A. cibarius, and A. thereius (the m-PCR method described by Douidah et al. [9]), or A. nitrofigilis and A. halophilus (the $16 \mathrm{~S}$ rRNA-RFLP method described by Figueras et al. [18]). As the $A$. trophiarum PCR identification of De Smet et al. [17] was designed to complement the previously published m-PCR of Douidah et al. [9], both methods were considered to be a single one when evaluating their performance (Tables 1 and 2).

All tested strains were grown on 5\% sheep blood agar for $48 \mathrm{~h}$ at $30^{\circ} \mathrm{C}$ under aerobic conditions. DNA was extracted using the InstaGene DNA Purification Matrix (Bio-Rad Laboratories, Hercules, CA, USA), and quantified using GeneQuant (Amersham Pharmacia Biotech, Cambridge, England) following the manufacturer's instructions. PCR amplifications were carried out in a 2720 Thermal Cycler (Applied Biosystems, Carlsbad, CA, USA) using the primers and conditions described in the different studies (Additional file 1: Table S2). The identity of all field strains was confirmed in a previous study using the $16 \mathrm{~S}$ rRNA-RFLP method described by Figueras et al. [19].

The evaluation of the performance of the methods was based on the percentage of strains of the targeted species that were correctly identified, and on the number of non-targeted species that gave erroneous results (Tables 1, 2 and Additional file 1: Table S1).

The literature review was carried out following PRISMA guidelines [20], using the Citations Search tool in the Web of Science ${ }^{\odot}$ V 5.8 in the Thomson Reuters ISI Web of Knowledge research platform (http://www. accesowok.fecyt.es). The platform was accessed using the Spanish national license via the Fundación Española para la Ciencia y la Tecnología (FECYT), and was last accessed on July 30th 2012. Each of the five studied molecular methods was searched by author, topic (Arcobacter), and year of publication to obtain the total number of citations for each method since publication until 2012. Citations were analyzed individually to find the total number of strains identified at the species level. The number of strains of each species identified using any of the compared methods, were used to make the calculations shown in Additional file 1: Table S3. In studies where no genotyping method was used, it was assumed that each isolate represented a strain.

\section{Results and discussion}

\section{Comparative performance of the five molecular methods}

The percentage of correctly identified strains obtained using the five identification methods, and the number of misidentified non-targeted species greatly depended upon the method used (Tables 1 and 2). The percentage of misidentified strains ranged from $16.8 \%$ to $67.4 \%$ (Table 2). The m-PCR method of Kabeya et al. [15] had the worst performance, and produced unreliable results for all three of its targeted species (Tables 1 and 2). Although all strains of $A$. cryaerophilus and $A$. skirrowii were correctly identified, a further eight and six nontargeted species, respectively, were mistakenly identified as one of these two species (Table 1). Furthermore, only $4.8 \%$ of the A. butzleri strains were correctly identified, with six non-targeted species being confused with this species (Tables 1 and 2). Globally, the Kabeya et al. m-PCR method correctly identified just 32.6\% (31/95) of the studied strains. Although this method was also designed to differentiate subgroups $1 \mathrm{~A}$ and $1 \mathrm{~B}$ of $A$. cryaerophilus, not all strains of these subgroups were correctly identified (Table 2). This correlates with the in silico observations of Douidah et al. [9] who reported that the primer used [15] were not specific enough to provide correct identification of A. cryaerophilus at the subgroup level. Further to this, Debruyne et al. [21] have suggested, that based on results of AFLP and hsp60 
Table 1 Performance of five molecular methods used for the identification of Arcobacter species in relation to a reference method $^{\mathrm{a}}$

\begin{tabular}{|c|c|c|c|c|c|c|c|c|c|c|c|c|c|c|c|c|}
\hline \multirow[b]{3}{*}{ Targeted species } & \multirow{3}{*}{ Strains ${ }^{c}$} & \multicolumn{3}{|c|}{ Houf et al. [14] } & \multicolumn{3}{|c|}{ Kabeya et al. [15] } & \multicolumn{3}{|c|}{$\begin{array}{l}\text { Figueras } \\
\text { et al. [18] }\end{array}$} & \multicolumn{3}{|c|}{$\begin{array}{l}\text { Pentimalli } \\
\text { et al. [16] }\end{array}$} & \multirow{2}{*}{\multicolumn{3}{|c|}{$\begin{array}{c}\text { Douidah et al. [9] } \\
\text { De Smet et al. [17] }\end{array}$}} \\
\hline & & & & & & & & & & & & & & & & \\
\hline & & A & B & C & A & B & C & A & B & C & A & B & C & A & B & C \\
\hline A. butzleri & 21 & $16 S$ & 100 & 0 & $23 S$ & 4.8 & 6 & $16 S$ & 100 & 3 & $16 S$ & 100 & 4 & 235 & 100 & 4 \\
\hline A. cryaerophilus & 19 & $23 S$ & 100 & 11 & $23 \mathrm{~S}$ & $100^{d}$ & 8 & $16 S$ & 63.2 & 0 & gyrA & 100 & 1 & gyrA & 100 & 1 \\
\hline A. skirrowii & 5 & $16 S$ & 100 & 4 & $23 \mathrm{~S}$ & 100 & 3 & $16 \mathrm{~S}$ & 100 & 0 & gyrA & 60 & 2 & $23 S$ & 100 & 0 \\
\hline A. cibarius & 8 & & & & & & & $16 \mathrm{~S}$ & 100 & 0 & gyrA & $0^{\mathrm{e}}$ & 0 & 235 & 100 & 0 \\
\hline A. thereius & 5 & & & & & & & & & & & & & 235 & 100 & 0 \\
\hline A. trophiarum & 3 & & & & & & & & & & & & & hsp60 & 100 & 0 \\
\hline A. nitrofigilis & 5 & & & & & & & $16 S$ & 100 & 0 & & & & & & \\
\hline A. halophilus & 1 & & & & & & & $16 \mathrm{~S}$ & 100 & 0 & & & & & & \\
\hline
\end{tabular}

(A) targeted genes, (B) percentage of correctly identified strains of the targeted species, and (C) number of non-targeted species misidentified as targeted ones.

${ }^{a}$ All strains were identified using the RFLP method of Figueras et al. [19] specifically designed to recognize all species.

${ }^{b}$ The method designed by De Smet et al. [17] only detects or identifies A. trophiarum, and was intended to complement the m-PCR of Douidah et al. [9]. Therefore, they are grouped together as a single method.

'The strains of the nine Arcobacter species not listed in this table $(n=28)$ belong to new species that were not targeted by the compared methods.

${ }^{\mathrm{d}}$ The method was designed to differentiate subgroups $1 \mathrm{~A}$ and $1 \mathrm{~B}$ of this species, but not all strains of these subgroups were well recognized (Table 2 ).

eDespite the eight strains of $A$. cibarius being correctly assigned to this species, none of them was considered to be correctly identified. This is because they were all confused with $A$. butzleri, and three of them with $A$. skirrowii, when using primers that targeted those species (Table 2).

analyses, the subgroup nomenclatures $1 \mathrm{~A}$ and $1 \mathrm{~B}$ should be abandoned.

The second least reliable method analysed was the m-PCR technique described by Houf et al. [14]. This correctly identified $55.8 \%$ (53/95) of the strains (Table 2), including all those belonging to its targeted species (A. butzleri, A. cryaerophilus, and A. skirrowii; Table 1). This method was $100 \%$ reliable for the identification of A. butzleri, and there was no confusion with other species. However, nine of the fourteen non-targeted species generated the typical amplicon of $A$. cryaerophilus; two that of A. skirrowii; and two simultaneously generated both amplicons (Tables 1 and 2). Only A. cibarius produced no amplification when using this method (Table 2). These results agree with previous studies that showed the existence of misidentifications when using this method [1,5-7].

A similar number of correctly identified strains $(83.2 \%)$ were obtained when using the other three evaluated methods (Pentimalli et al. [16]; the combined method of Douidah et al. [9] and De Smet et al. [17]; and Figueras et al. [18]). However, the number of misidentified non-targeted species differed depending upon the method used (Tables 1 and 2). Most misidentification occurred when using the method of Pentimalli et al. [16]. In this case, four non-targeted species were confused with $A$. butzleri, one with $A$. cryaerophilus, and two with $A$. skirrowii (Tables 1 and 2). Furthermore, the expected amplicons for A. butzleri and A. skirrowii in individual reactions were also obtained for the eight and three strains of $A$. cibarius, respectively (Table 2 ). Nevertheless, no cross-reaction with non-targeted species occurred when using primers designed for A. cibarius that reacted only with the eight strains of this species. The combined method of Douidah et al. [9] and De Smet et al. [17], misidentified four of the non-targeted species (Arcobacter defluvii, Arcobacter ellisii, Arcobacter venerupis, and Arcobacter suis) as A. butzleri, and two of the three strains of $A$. ellisii as $A$. cryaerophilus (Table 2). The method performed correctly for the four remaining targeted species. Finally, the $16 \mathrm{~S}$ rRNA-RFLP designed by Figueras et al. [18] was found to misidentify three species (A. trophiarum, A. thereius, and some A. cryaerophilus strains) as $A$. butzleri. Further to this, $A$. suis, and $A$. defluvii produced the same pattern, and two species (A. venerupis, and Arcobacter marinus) a very similar one (Table 2). Because of these limitations, this method has recently been updated with new endonucleases; these produced specific results for all strains and species [19]. This updated protocol was the one used to identify all strains used in this study.

\section{Comparative evaluation of the targeted genes and designed primers}

When the results were evaluated in relation to genes used to identify the species, it was observed that the $23 \mathrm{~S}$ rRNA gene regions targeted in the Kabeya et al. [15] method for A. butzleri, A. cryaerophilus, and A. skirrowii were unreliable, as was the region employed in the Houf et al. method [14] for A. cryaerophilus (Tables 1 and Additional file 1: Table S2). However, the regions of the $23 \mathrm{~S}$ rRNA gene targeted by the m-PCR method of Douidah et al. [9] were 100\% reliable for the detection of $A$. skirrowii, A. cibarius, and A. thereius, but not for 
Table 2 Identification results obtained for 95 strains of 17 Arcobacter spp. when using the five different PCR identification methods

\begin{tabular}{|c|c|c|c|c|c|c|}
\hline Species & Strains $^{a}$ & $\begin{array}{l}\text { Houf } \\
\text { et al. [14] }\end{array}$ & $\begin{array}{l}\text { Kabeya } \\
\text { et al. [15] }\end{array}$ & $\begin{array}{l}\text { Figueras } \\
\text { et al. }[18]^{\mathrm{b}}\end{array}$ & $\begin{array}{l}\text { Pentimalli } \\
\text { et al. [16] }\end{array}$ & $\begin{array}{l}\text { Douidah et al. [9] } \\
\text { De Smet et al. [17] }\end{array}$ \\
\hline \multirow[t]{3}{*}{ A. butzleri (Ab) } & 21 & $21 \mathrm{Ab}$ & $1 A b^{d}$ & $21 \mathrm{Ab}$ & $21 \mathrm{Ab}$ & $21 \mathrm{Ab}$ \\
\hline & & & $15 A b+A c r 1 B^{e}$ & & & \\
\hline & & & $5 N A^{f}$ & & & \\
\hline \multirow[t]{2}{*}{ A. cryaerophilus (Acr) } & 19 & $19 \mathrm{Acr}$ & $19 \mathrm{Acr}$ & $12 \mathrm{Acr}$ & 19 Acr & $19 \mathrm{Acr}$ \\
\hline & & & & $7 \mathrm{Ab}$ & & \\
\hline \multirow[t]{2}{*}{$\operatorname{Acr} 1 A(n=6)$} & & & $5 \operatorname{Acr} 1 A^{d}$ & 6 Acry1 $A^{d}$ & & \\
\hline & & & 1 Acr1B & & & \\
\hline \multirow[t]{2}{*}{$\operatorname{Acr} 1 B(n=6)$} & & & 5 Acr1B & 6 Acry1B & & \\
\hline & & & $1 \operatorname{Acr} 1 \mathrm{~A}$ & & & \\
\hline \multirow[t]{2}{*}{ A. skirrowii (Aski) } & 5 & 5 Aski & 5 Aski & 5 Aski & 3 Aski $^{\mathrm{d}, \mathrm{g}}$ & 5 Aski \\
\hline & & & & & $2 \mathrm{NA}$ & \\
\hline \multirow[t]{3}{*}{ A. nitrofigilis (Anit) } & 5 & 5 Aski & $4 A c r 1 B^{d}$ & 5 Anit & $2 \mathrm{Ab}$ & NA \\
\hline & & & $1 \mathrm{Ab}+\mathrm{Acr} 1 \mathrm{~B}$ & & $2 \mathrm{Acr}$ & \\
\hline & & & & & $3 N A^{* d}$ & \\
\hline A. halophilus (Ahalo) & 1 & $1 \mathrm{Aski}+\mathrm{Acr}$ & 1 Aski & 1 Ahalo & $N A^{*}$ & NA \\
\hline \multirow[t]{3}{*}{ A. cibarius (Acib) } & 8 & $8 \mathrm{NA}$ & 3 Aski $^{d}$ & 8 Acib & $8 \mathrm{Ab}$ & 8 Acib \\
\hline & & & 5 Aski + Acr1B & & 8 Acib & \\
\hline & & & & & 3 Aski & \\
\hline \multirow[t]{4}{*}{ A. thereius (Ather) } & 5 & $5 \mathrm{Acr}$ & $1 \mathrm{Ab}$ & $5 \mathrm{Ab}$ & $5 \mathrm{NA}^{*}$ & 5 Ather \\
\hline & & & $2 A b+A c r 1 B^{d}$ & & & \\
\hline & & & 1 Acr1B & & & \\
\hline & & & $1 \mathrm{NA}$ & & & \\
\hline A. mytili (Amyt) & 3 & 3 Aski & 3 Aski & 3 Amyt & $3 \mathrm{NA}^{*}$ & $3 \mathrm{NA}$ \\
\hline A. marinus (Amar) & 1 & $1 \mathrm{Acr}$ & $1 \mathrm{NA}$ & $1 \mathrm{Amar}^{\mathrm{h}}$ & $1 \mathrm{Ab}$ & $1 \mathrm{NA}$ \\
\hline A. molluscorum (Amoll) & 3 & $3 \mathrm{Aski}+\mathrm{Acr}$ & $3 \mathrm{NA}$ & 3 Amoll & $3 \mathrm{NA}^{*}$ & $3 N A$ \\
\hline A. defluvii (Adef) & 11 & $11 \mathrm{Acr}$ & $11 \mathrm{Ab}$ & 11 Adef & $11 \mathrm{NA}^{* \mathrm{~d}}$ & $11 \mathrm{Ab}$ \\
\hline \multirow[t]{2}{*}{ A. trophiarum (Atroph) } & 3 & $3 \mathrm{Acr}$ & $2 A b^{d}$ & $3 \mathrm{Ab}$ & $3 \mathrm{NA}^{*}$ & 3 Atroph \\
\hline & & & $1 \mathrm{NA}$ & & & \\
\hline \multirow[t]{2}{*}{ A. ellisii (Aelli) } & 3 & $3 \mathrm{Acr}$ & $3 \mathrm{Acr} 1 \mathrm{~A}+\mathrm{Acr1B}$ & 3 Aelli & 2 Aski & $1 \mathrm{Ab}$ \\
\hline & & & & & $1 N A^{* d}$ & $2 \mathrm{Ab}+\mathrm{Acr}^{\mathrm{d}}$ \\
\hline A. bivalviorum (Abiv) & 3 & $3 \mathrm{Acr}$ & 3 Acr1B & 3 Abiv & $3 \mathrm{NA}$ & $3 N A$ \\
\hline A. venerupis (Aven) & 1 & $1 \mathrm{Acr}$ & $1 \mathrm{Ab}$ & 1 Aven $^{\text {h }}$ & $1 \mathrm{Ab}$ & $1 \mathrm{Ab}$ \\
\hline A. cloacae (Acloa) & 2 & $2 \mathrm{Acr}$ & $2 A b+A c r 1 B$ & 2 Acloa & $2 \mathrm{NA}^{*}$ & $2 N A$ \\
\hline A. suis (Asuis) & 1 & $1 \mathrm{Acr}$ & 1 Acr1A & 1 Adef & $1 \mathrm{NA}$ & $1 \mathrm{Ab}$ \\
\hline Correctly identified strains & & 53 (55.8\%) & $31(32.6 \%)$ & 79 (83.2\%) & 79 (83.2\%) & $79(83.2 \%)$ \\
\hline
\end{tabular}

${ }^{a}$ All strains were identified using the RFLP method of Figueras et al. [19] that had been specifically designed to recognize all species. The new species Arcobacter anaerophilus was not tested as it had only recently been described [8]. However, a computer simulation of the digestion of the 16S rRNA gene sequence of the type strain of this species (Accession number FR686494) using the Msel endonuclease [18,19] showed a species-specific RFLP pattern (658, 138, 60, 52, 41, 34, 28, 12, 3 bp). ${ }^{b}$ As this method was designed for A. butzleri, A. cryaerophilus, A. cibarius, A. skirrowii, A. nitrofigilis and A. halophilus [18], the results for strains of other species were interpreted based on the RFLP patterns described in subsequent publications [5-7,23-25].

${ }^{\mathrm{C}}$ The method designed by De Smet et al. [17] only detects or identifies A. trophiarum, and was intended to complement the m-PCR of Douidah et al. [9]. Therefore, they are grouped together as a single method.

${ }^{d}$ Result obtained for the type strain.

especies $A+$ species $B$ refers to the fact that the expected amplicon for species A and B were obtained in the same reaction.

${ }^{\mathrm{f}} \mathrm{NA}$ or NA*: No amplification of a band of the expected size, or $\left(^{*}\right)$ band/s of another size were obtained.

${ }^{9}$ When different results were obtained using the four individual PCR reactions designed by Pentimalli et al. [16] for A. butzleri, A. cryaerophilus, A. skirrowii, and A. cibarius, they are shown on separate lines.

${ }^{\mathrm{h}} A$. venerupis produced a pattern very similar to that of $A$. marinus [19]. 
A. butzleri (Tables 1, 2 and Additional file 1: Table S2). With regard to the gyrA gene, the region used for the identification of $A$. cryaerophilus in the latter method, and the one in the method of Pentimalli et al. [16] were unreliable. Despite all strains of $A$. cryaerophilus being correctly identified, $A$. ellisii was confused with this species when using the Douidah et al. [9] method, and with A. skirrowii when using the Pentimalli et al. [16] method (Tables 1 and 2). The main reason for the poor performance of the targeted regions of $23 \mathrm{~S}$ rRNA or $g y r A$ genes (Additional file 1: Table S2) is the limited amount of sequences used to derive the primers. For instance, the sequences of the 23S rRNA gene are, at the time of writing, only available for eight of the seventeen known Arcobacter species (A. butzleri, A. cryaerophilus, A. skirrowii, A. cibarius, A. nitrofigilis, A. thereius, Arcobacter mytili, and A. trophiarum), and the gyrA gene is only available for seven species (A. butzleri, A. cryaerophilus, A. skirrowii, A. cibarius, $A$. nitrofigilis, $A$. marinus, and $A$. halophilus). In contrast, the sequences of the $16 \mathrm{~S}$ rRNA gene are available for all species of the genus, and this has enabled the identification of endonucleases that produce specific patterns for all species; as described in the recently published update of the 16S rRNA-RFLP method [19]. The 16S rRNA gene has also been used to design specific primers for A. skirrowii and $A$. butzleri in the Houf et al. method [14], and for $A$. butzleri by Pentimalli et al. [16]. However, only the primers that targeted the $16 \mathrm{~S}$ rRNA region chosen by Houf et al. [14] for the identification of A. butzleri (Additional file 1: Table S2) were $100 \%$ specific, and showed no crossreaction with other species (Tables 1 and 2).

\section{Literature review of the studied methods}

The results of the literature review, which summarised the total number of strains and species identified using any of the five compared methods (Additional file 1: Table S3), revealed that the m-PCR method of Houf et al. [14] was the most globally referenced, with $71.9 \%$ $(123 / 171)$ of all citations. This method was used to identify $64.8 \%(2735 / 4223)$ of the strains recorded in the literature since 2000 (Additional file 1: Table S3). The next most frequently used methods were the $16 \mathrm{~S}$ rDNARFLP of Figueras et al. [18] and the m-PCR of Douidah et al. [9], which were used to identify $14.6 \%$ and $13.4 \%$ of strains, respectively (Additional file 1: Table S3). The overall most prevalent species were A. butzleri $(63.7 \%$ of strains), followed by $A$. cryaerophilus (27.3\%), and $A$. skirrowii (4.9\%) (Additional file 1: Table S3). The other 14 species represented only $4.1 \%$ of the recovered strains (Additional file 1: Table S3). The species diversity may be influenced by the different origins of the strains and/ or the isolation methods used in the analysed studies.

When considering the results obtained in the present study, with those of the literature review, the strains identified as $A$. butzleri (64.5\%) using the m-PCR designed by Houf et al. [14] could be considered to be correctly identified (Additional file 1: Table S3). However, the use of this method has probably led to a global overestimation of the number of $A$. cryaerophilus and $A$. skirrowii as some of the strains identified are likely to belong to other species (Tables 1 and 2). For example, when Atabay et al. [22] used the Houf et al. method [14] they identified six A. skirrowii strains that were not able to hydrolyze indoxyl acetate, despite this being a typical phenotypic characteristic of the species. Interestingly, A. mytili, one of only two Arcobacter species (along with Arcobacter molluscorum) unable to hydrolyze indoxyl acetate, produces the typical band of $A$. skirrowii when the m-PCR method of Houf et al. [14] is used. Therefore, the six strains identified by Atabay et al. [22] may belong to that species. Further evidence for this confusion of results can be found in a study on the prevalence of Arcobacter in meat and shellfish in which strains belonging to $A$. nitrofigilis and $A$. thereius were recognized [23]. This is because contradictory results were seen when using two identification methods in parallel $[14,18]$. When using the Houf method [14], A. nitrofigilis produced the expected amplicon for $A$. skirrowii and $A$. thereius the amplicon expected for $A$. cryaerophilus. However, when using the method of Figueras et al. [18] the expected 16S rRNA-RFLP pattern of $A$. nitrofigilis and $A$. butzleri was obtained for the A. nitrofigilis and $A$. thereius strains, respectively. The correct identity of these strains was confirmed as $A$. nitrofigilis and $A$. thereius through sequencing of the $16 \mathrm{~S}$ rRNA and/or $r p o B$ genes [23]. This sequencing approach resolved the discrepancies observed between the two identification methods $[14,18]$ and has also led to the discovery of the species A. mytili, A. molluscorum, $A$. defluvii, A. ellisii, Arcobacter bivalviorum, A. venerupis, A. cloacae, and A. suis [5-7,24-26].

The use of the m-PCR method of Douidah et al. [9] in combination with the PCR method of De Smet et al. [17] enabled $A$. thereius (17.6\%, 100/567), A. trophiarum (1.8\%, 10/567), and A. cibarius $(0.2 \%, 1 / 567)$ to be recognized in two independent studies [27,28] (Additional file 1: Table S3). Nevertheless, there is a weakness in this approach as the strains of four non-targeted species may be misidentified as the more frequently isolated $A$. butzleri (Tables 1 and 2).

Finally, with regard to studies that used the methodology designed by Kabeya et al. [15], our results revealed that all of the targeted species may have been overestimated; this is because 12 of the 14 non-targeted species could be misidentified (Tables 1 and 2). No studies were found that used the PCR method of Pentimalli et al. [16], and our results indicate that this method is not reliable (Tables 1 and 2). 


\section{Conclusion}

In this study, the performance of five different PCR methods used to identify all known Arcobacter spp. has been compared for the first time. None of the compared methods were completely reliable, and they displayed different misidentification rates for both targeted and non-targeted species; many of which have been described after the publication of the method. The current study has highlighted the limitations of the compared methods. We consider the way forward to be the use of the more reliable methods in parallel for verification of identity of the isolates. Our results suggest that the currently known diversity of Arcobacter spp. in different environments will change in the future as reliable identification methods, such as the updated 16S rRNA-RFLP method [19], are applied.

\section{Additional file}

Additional file 1: Table S1. Strains of Arcobacter spp. used in the study. Table S2. Targeted genes and PCR conditions of the compared methods. Table S3. Literature review of 171 studies (2000-2012) that identified 4223 strains of Arcobacter using the five compared PCR methods.

\section{Competing interests}

The authors declared that they have no competing interests.

\section{Authors' contributions}

$\mathrm{AL}$ carried out the experiments, the literature review, and was the principal author of the manuscript. MJF designed the research project, evaluated results, helped draft the manuscript, and supervised AL. Both authors read and approved the final manuscript.

\section{Acknowledgments}

The authors thank Dr. Maqsudul Alam (University of Hawaii, Manoa, $\mathrm{HI}$,), Dr. Kurt Houf (Ghent University, Belgium), and Dr. Nalini Chinivasagam (Animal Research Institute, Queensland, Australia) for kindly providing Arcobacter strains. AL is thankful to the Universitat Rovira i Virgili for a doctoral grant and to CONICYT, Chile for financial support through Becas Chile. This work was supported in part by the Ministerio de Ciencia e Innovación (Spain) project AGL2011-30461-C02-02 and by funding from the European Union Seventh Framework Programme (FP7/2007-2013) under grant agreement n 311846).

Received: 7 February 2013 Accepted: 27 September 2013

Published: 3 October 2013

\section{References}

1. Collado L, Figueras MJ: Taxonomy, epidemiology and clinical relevance of the genus Arcobacter. Clin Microbiol Rev 2011, 24:174-192.

2. Collado L, Inza I, Guarro J, Figueras MJ: Presence of Arcobacter spp. in environmental waters correlates with high levels of fecal pollution. Environ Microbio/ 2008, 10:1635-1640.

3. Collado L, Kasimir G, Perez U, Bosch A, Pinto R, Saucedo G, Huguet JM Figueras MJ: Occurrence and diversity of Arcobacter spp. along the Llobregat river catchment, at sewage effluents and in a drinking water treatment plant. Water Res 2010, 44:3696-3702.

4. Vandamme $P$, Falsen E, Rossau R, Hoste B, Segers P, Tytgat R, De Ley J: Revision of Campylobacter, Helicobacter, and Wolinella taxonomy: emendation of generic descriptions and proposal of Arcobacter gen. nov. Int J Syst Bacteriol 1991, 41:88-103.

5. Figueras MJ, Levican A, Collado L, Inza MI, Yustes C: Arcobacter ellisii sp. nov., isolated from mussels. Syst Appl Microbiol 2011, 34:414-418.
6. Levican A, Collado L, Aguilar C, Yustes C, Diéguez AL, Romalde JL, Figueras MJ: Arcobacter bivalviorum sp. nov. and Arcobacter venerupis sp. nov., new species isolated from shellfish. Syst Appl Microbiol 2012, 35:133-138.

7. Levican A, Collado L, Figueras MJ: Arcobacter cloacae sp. nov. and Arcobacter suis sp. nov., new species isolated from food and sewage. Syst Appl Microbiol 2013, 36:22-27.

8. Sasi Jyothsna TS, Rahul K, Ramaprasad EV, Sasikala C, Ramana CV: Arcobacter anaerophilus sp. nov., isolated from an estuarine sediment and emended description of the genus Arcobacter. Int J Syst Evol Microbiol. doi:10.1099/ ijs.0.054155-0. In press.

9. Douidah L, De Zutter L, Vandamme P, Houf K: Identification of five human and mammal associated Arcobacter species by a novel multiplex-PCR assay. J Microbiol Methods 2010, 80:281-286.

10. Bastyns K, Cartuyvelsi D, Chapelle S, Vandamme P, Goosens H, De Watcher $\mathrm{R}$ : A variable $23 \mathrm{~S}$ rDNA region is a useful discriminating target for genusspecific and species-specific PCR amplification in Arcobacter species. Syst Appl Microbiol 1995, 18:353-356.

11. Moreno Y, Botella S, Alonso JL, Ferrus MA, Hernandez M, Hernandez J: Specific detection of Arcobacter and Campylobacter strains in water and sewage by PCR and fluorescent in situ hybridization. Appl Env Microbiol 2004, 69:1181-1186.

12. Abdelbaqi K, Buissonniere A, Prouzet-Mauleon V, Gresser J, Wesley I, Mégraud F, Ménard A: Development of a real-time fluorescence resonance energy transfer PCR to detect Arcobacter species. J Clin Microbiol 2007, 45:3015-3021.

13. González A, Moreno Y, Gonzalez R, Hernández J, Ferrus MA: Development of a simple and rapid method based on polymerase chain reactionbased restriction fragment length polymorphism analysis to differentiate Helicobacter, Campylobacter, and Arcobacter species. Curr Microbiol 2006, 53:416-421.

14. Houf K, Tutenel A, De Zutter L, Van Hoof J, Vandamme P: Development of a multiplex PCR assay for the simultaneous detection and identification of Arcobacter butzleri, Arcobacter cryaerophilus and Arcobacter skirrowii. FEMS Microbiol Lett 2000, 193:89-94.

15. Kabeya H, Kobayashi Y, Maruyama S, Mikami T: Distribution of Arcobacter species among livestock in Japan. Vet Microbiol 2003, 93:153-158.

16. Pentimalli D, Pegels N, Garcia T, Martin R, González I: Specific PCR detection of Arcobacter butzleri, Arcobacter cryaerophilus, Arcobacter skirrowii, and Arcobacter cibarius in chicken meat. J Food Prot 2009, 72:1491-1495.

17. De Smet S, Vandamme P, De Zutter L, On S, Douidah L, Houf K: Arcobacter trophiarum sp. nov. isolated from fattening pigs. Int I Syst Evol Microbiol 2011, 63:356-361.

18. Figueras MJ, Collado L, Guarro J: A new $16 \mathrm{~S}$ rDNA-RFLP method for the discrimination of the accepted species of Arcobacter. Diagn Microbiol Infect Dis 2008, 62:11-15.

19. Figueras MJ, Levican A, Collado L: Updated $16 \mathrm{~S}$ rRNA-RFLP method for the identification of all currently characterized Arcobacter spp. BMC Microbiol 2012, 12:292.

20. Liberati A, Altman DG, Tetzlaff J, Mulrow C, Gøtzsche PC, Loannidis JPA, Clarke M, Devereaux PJ, Kleijnen J, Moher D: The PRISMA statement for reporting systematic reviews and meta-analyses of studies that evaluate health care interventions: explanation and elaboration. PLoS Med 2009, 6(7):e1000100

21. Debruyne L, Houf K, Douidah L, De Smet S, Vandamme P: Reassessment of the taxonomy of Arcobacter cryaerophilus. Syst Appl Microbiol 2010, 33:7-14

22. Atabay HI, Waino M, Madsen M: Detection and diversity of various 754 Arcobacter species in Danish poultry. Int J Food Microbiol 2006 109:139-145.

23. Collado L, Guarro J, Figueras MJ: Prevalence of Arcobacter in meat and shellfish. J Food Prot 2009, 72:1102-1106.

24. Collado L, Cleenwerck I, Van Trappen S, De Vos P, Figueras MJ: Arcobacter mytili sp. nov., an indoxyl acetate-hydrolysis-negative bacterium isolated from mussels. Int J Syst Evol Microbiol 2009, 59:1391-1396.

25. Figueras MJ, Collado L, Levican A, Perez J, Solsona MJ, Yustes C: Arcobacter molluscorum sp. nov., new species isolated from shellfish. Syst Appl Microbiol 2011, 34:105-109.

26. Collado L, Levican A, Perez J, Figueras MJ: Arcobacter defluvii sp. nov. isolated from sewage. Int J Syst Evol Microbiol 2011, 61:1895-1901. 
27. De Smet $S$, De Zutter L, Debruyne L, Vangroenweghe F, Vandamme $P$,

Houf K: Arcobacter population dynamics in pigs on farrow-to-finish farms. Appl Environ Microbiol 2011, 77:1732-1738.

28. De Smet S, De Zutter L, Houf K: Small ruminants as carriers of the emerging foodborne pathogen Arcobacter on small and medium farms. Small Ruminants Res 2011, 97:124-129.

doi:10.1186/1471-2180-13-220

Cite this article as: Levican and Figueras: Performance of five molecular methods for monitoring Arcobacter spp. BMC Microbiology 2013 13:220.

\section{Submit your next manuscript to BioMed Central and take full advantage of:}

- Convenient online submission

- Thorough peer review

- No space constraints or color figure charges

- Immediate publication on acceptance

- Inclusion in PubMed, CAS, Scopus and Google Scholar

- Research which is freely available for redistribution 